\title{
Proteomic identification of OsCYP2, a rice cyclophilin that confers salt tolerance in rice (Oryza sativa L.) seedlings when overexpressed
}

\author{
Song-Lin Ruan ${ }^{1,2^{*}}$, Hua-Sheng Ma ${ }^{1 *}$, Shi-Heng Wang ${ }^{1}$, Ya-Ping Fu², Ya Xin ${ }^{1}$, Wen-Zhen Liu², Fang Wang ${ }^{1}$,
} Jian-Xin Tong ${ }^{1}$, Shu-Zhen Wang ${ }^{1}$, Hui-Zhe Chen ${ }^{2}$

\begin{abstract}
Background: High Salinity is a major environmental stress influencing growth and development of rice. Comparative proteomic analysis of hybrid rice shoot proteins from Shanyou 10 seedlings, a salt-tolerant hybrid variety, and Liangyoupeijiu seedlings, a salt-sensitive hybrid variety, was performed to identify new components involved in salt-stress signaling.
\end{abstract}

Results: Phenotypic analysis of one protein that was upregulated during salt-induced stress, cyclophilin 2 (OsCYP2), indicated that OSCYP2 transgenic rice seedlings had better tolerance to salt stress than did wild-type seedlings. Interestingly, wild-type seedlings exhibited a marked reduction in maximal photochemical efficiency under salt stress, whereas no such change was observed for OsCYP2-transgenic seedlings. OsCYP2-transgenic seedlings had lower levels of lipid peroxidation products and higher activities of antioxidant enzymes than wild-type seedlings. Spatiotemporal expression analysis of OsCYP2 showed that it could be induced by salt stress in both Shanyou 10 and Liangyoupeijiu seedlings, but Shanyou 10 seedlings showed higher OsCYP2 expression levels. Moreover, circadian rhythm expression of OSCYP2 in Shanyou 10 seedlings occurred earlier than in Liangyoupeijiu seedlings. Treatment with PEG, heat, or ABA induced OsCYP2 expression in Shanyou 10 seedlings but inhibited its expression in Liangyoupeijiu seedlings. Cold stress inhibited OsCYP2 expression in Shanyou 10 and Liangyoupeijiu seedlings. In addition, OsCYP2 was strongly expressed in shoots but rarely in roots in two rice hybrid varieties.

Conclusions: Together, these data suggest that OsCYP2 may act as a key regulator that controls ROS level by modulating activities of antioxidant enzymes at translation level. OsCYP2 expression is not only induced by salt stress, but also regulated by circadian rhythm. Moreover, OsCYP2 is also likely to act as a key component that is involved in signal pathways of other types of stresses-PEG, heat, cold, or ABA.

\section{Background}

Rice is a salt-sensitive cereal crop. High salinity may cause delayed seed germination, slow seedling growth, and reduced rate of seed set, leading to decreased rice yield. These disorders are generally due to the combined effects of ion imbalance, hyperosmotic stress, and oxidative damage. In the early period, rice can rapidly perceive a salt stress signal via plasma membrane receptors in root cells and can rapidly initiate an intracellular

\footnotetext{
* Correspondence: ruansl1@hotmail.com; hzhsma@163.com 'Plant Molecular Biology \& Proteomics Lab, Institute of Biotechnology, Hangzhou Academy of Agricultural Sciences, Hangzhou 310024, PR China Full list of author information is available at the end of the article
}

signal that modulates gene expression to elicit an adaptive response.

Functional genomics is an effective tool for identifying new genes, determining gene expression patterns in response to salt stress, and understanding their functions in stress adaptation. Initially, gene expression is examined at the mRNA level using large-scale screening techniques such as cDNA microarrays, serial analysis of gene expression, and cDNA-amplified fragment-length polymorphism. cDNA microarrays containing 1728 cDNAs were used to analyze gene expression profiles during the initial phase of salt stress in rice roots, and found that approximately $10 \%$ of the transcripts in Pokkali were significantly upregulated or downregulated

\section{Biomed Central}

(c) 2011 Ruan et al; licensee BioMed Central Ltd. This is an Open Access article distributed under the terms of the Creative Commons Attribution License (http://creativecommons.org/licenses/by/2.0), which permits unrestricted use, distribution, and reproduction in any medium, provided the original work is properly cited. 
within $1 \mathrm{~h}$ of salt stress [1]. To date, cDNA microarray analyses have identified approximately 450 salt-responsive unigenes in shoots of the highly salt-tolerant rice variety, Nona Bokra, and most of them were not known to be involved in salt stress [2]. In addition, forward and reverse genetics have identified gene functions during salt stress. Interestingly, map-based cloning was used to isolate a rice quantitative trait loci gene, SKC1 that encoded an HKT-type transporter selective for $\mathrm{Na}^{+}$. Analysis of transgenic rice plants with loss-of-function or gain-of-function phenotypes that were changed by forward and reverse genetics revealed that SKC1 was involved in regulating $\mathrm{K}^{+} / \mathrm{Na}^{+}$homeostasis under salt stress [3]. Also, in Arabidopsis, overexpression of SOS1, which encoded a plasma membrane $\mathrm{Na}^{+} / \mathrm{H}^{+}$antiporter, improved salt tolerance [4].

Recently, proteome profiles of rice in response to salt stress were presented for various tissues or organs such as roots, leaf lamina, leaf sheaths and young panicles [5-8]. Although some differential proteins of interest have been identified, little is known about the functions of these proteins.

Here, OsCYP2, a salt-induced rice cyclophilin, was separated and identified by 2-DE, MALDI-TOF MS and ESI-MS/MS. OsCYP2 had peptidyl-prolyl cis-trans isomerase (PPIase or rotamase) activity that was specifically inhibited by cyclosporine A [9]. Moreover, OsCYP2 lacks introns, and the 5' end of transcript contains an AT-rich region, suggesting that OsCYP2 was likely to be preferentially translated during stress conditions [10]. Actually, OsCYP2 could respond to multiple environmental stresses such as high salt, drought, heat and oxidative stress. For example, heterologous expression of OsCYP2 was able to enhance ability of $E$. coli to survive, to complement the yeast mutant lacking native OsCYP2 and to improve the growth of wild type yeast under the above mentioned abiotic stresses [9]. In addition, significantly differential changes in transcript abundance of OsCYP2 were found in shoots of salt sensitive (IR64) and tolerant (Pokkali) rice cultivars at different developmental stages under normal and salt stress conditions [9].

We have therefore focused on the effect of OsCYP2 expression on salt tolerance in rice seedlings. Overexpression of OsCYP2 conferred salt tolerance in transgenic rice seedlings. Although OsCYP2-transgenic seedlings did not predominate over wild-type seedlings in ion homeostasis $\left(\mathrm{K}^{+} / \mathrm{Na}^{+}\right.$ratio) and osmotic regulation (free proline), they displayed lower levels of lipid peroxidation products and higher activities of antioxidant enzymes than wild-type seedlings, suggesting that the involvement of OsCYP2 in the response of rice seedling to salt stress is required, but also it can enhance salt tolerance in transgenic rice seedlings by controlling ROS levels. In addition to salt stress, OsCYP2 can respond to other types of stresses, such as drought, heat and cold, indicating that OsCYP2 is likely to act as a general integrator of environmental stresses.

\section{Results}

\section{Evaluation of the salt tolerance of two rice hybrid} varieties

To compare the salt tolerance of the two rice hybrid varieties, Shanyou 10 and Liangyoupeijiu, relative length and dry weight of shoots and roots were determined after exposure to salt stress, respectively. The roots and shoots of Shanyou 10 were longer and heavier than those of Liangyoupeijiu (Figure 1B, C). Phenotypic analysis showed that Shanyou 10 seedlings grew faster than Liangyoupeijiu seedlings under salt stress conditions (Figure 1A), suggesting that Shanyou 10 seedlings were relatively more tolerant to salt.

\section{Separation and identification of differentially expressed salt-responsive proteins of rice seedlings}

To understand the differences between Shanyou 10 and Liangyoupeijiu at the protein expression level, 2-DE and MS were used to separate and identify differentially expressed salt-responsive proteins of rice seedlings in Shanyou 10 and Liangyoupeijiu. More than 1050 rice shoot proteins (more than 950 proteins from IPG5-8 and more than 100 proteins from IPG7-10) were detected by image match analysis. Of these, 34 proteins were up- or downregulated in response to salt stress. Nine upregulated proteins consistently showed significant and reproducible increases in abundance (1- to 4-fold) under $\mathrm{NaCl}$ stress (Figure 2A, B) and were selected for MALDI-TOF MS analysis. They were identified as a putative glutathione S-transferase, manganese superoxide dismutase, dehydroascorbate reductase (free radical scavenging), a putative phosphogluconate dehydrogenase (pentose phosphate pathway), putative l-aspartate oxidase (protein metabolism), putative cold shock protein-1(cold stress response), prohibitin (cell proliferation), a putative membrane protein (unknown function), a putative oxygenevolving enhancer protein 3-1 (photosynthesis) and cyclophilin 2 (OsCYP2)(protein folding) (Table 1).

The $\mathrm{p} 8$ protein spot in Figure 2B was selected for further analysis using ESI-MS/MS to determine peptide sequence. Three peptides from the $\mathrm{p} 8$ spot were sequenced and matched to OsCYP2 in the MASCOT database (Table 2). Two peptides (m/z 1424.64 and 1656.64) were found in matched peptides from PMF (Additional file 1). These results identified the p8 spot as OsCYP2. The other protein spots were also validated using ESI-MS/MS (Additional file 2).

OsCYP2 (accession no. AAA57046) was predicted to encode a protein of 172 amino acids with a molecular mass of $18.6 \mathrm{kDa}$ and a $p I$ of 8.61.In the conserved 
A

$100 \mathrm{mM} \mathrm{NaCl}$

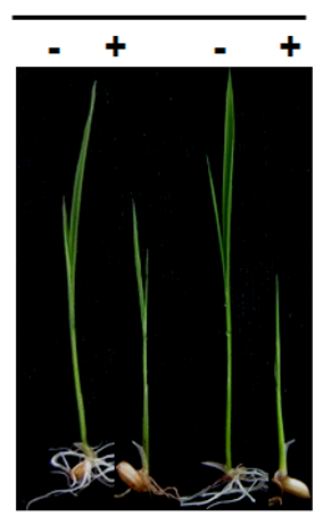

Shanyou10 Liangyoupeijiu

B

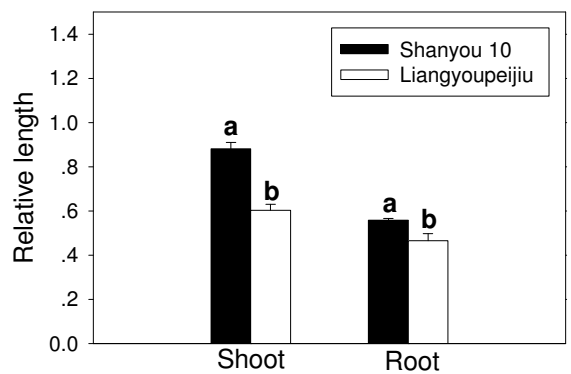

C

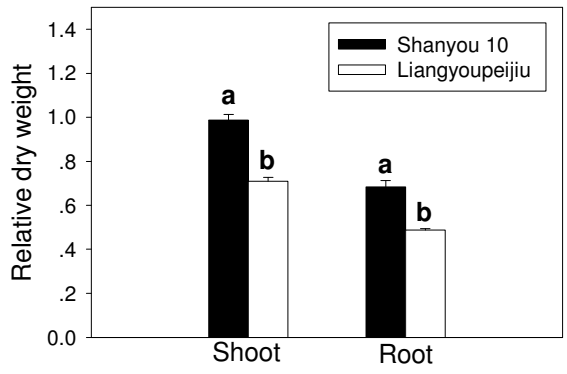

Figure 1 Phenotypes of Shanyou 10 and Liangyoupeijiu seedlings after salt stress. (A) Phenotypes of 10-day-old seedlings of Shanyou 10 and Liangyoupeijiu after salt stress (100 mM NaCl), as indicated by $(+)$, or under normal conditions (no $\mathrm{NaCl}$ ), as indicated by (-). (B) Relative length of shoots and roots of Shanyou 10 and Liangyoupeijiu seedlings. (C) Relative dry weight of shoots and roots of Shanyou 10 and Liangyoupeijiu seedlings. The distance from the basal part of shoot to tip of the longest leaf was calculated as the length of seedling. The percentage of relative FW, DW, or shoot/root length of the salt treated samples was calculated in relation to non-treated. Data represent the average of four treatments (mean \pm S.E.). Identical letters above a pair of bars indicate that the values are not significantly different at the $p=0.05$ level according to Duncan's multiple range test. region of OsCYP2, the residues His-61, Arg-62, Phe-67, Gln-118, Phe-120, Trp-128 and His-33 appeared to be associated with PPIase catalysis. Three of these, including His-61, Arg-62 and Phe-120, are most essential for PPIase activity of OsCYP2. The residue Trp-128 is a binding site of OsCYP2 with immunosuppressant cyclosporin A (Figure 3A). OsCYP2 had significant homology with other known cyclophilins from various plant species (Figure 3A). The deduced amino acid sequence of OsCYP2 displayed higher identity with the cyclophilins of three cereal crops, T. aestivum, Zea mays and Sorghum bicolor (86\% each), while OsCYP2 showed relatively lower identity with three cyclophilins of Arabidopsis, including AtCYP19-2 (78\%), AtCYP20-2 (63\%) and AtCYP20-3 (58\%). Moreover, a closer relationship between OsCYP2 and the cyclophilins of three cereal crops was observed compared to Arabidopsis (Figure 3B).

\section{Phenotypic identification of OsCYP2 transgenic rice seedlings under salt stress}

To understand the response of transgenic rice seedlings with $O s C Y P 2$ overexpression to salt stress, we introduced this gene into wild-type rice $(O$. sativa $\mathrm{cv}$. Aichi ashahi) to obtain T3 transgenic seedlings with single copy insertion (Additional file 3). Ten-day-old transgenic and wild-type seedlings were treated with $200 \mathrm{mM}$ $\mathrm{NaCl}$. After 5 days, leaves of wild-type seedlings exhibited the chlorotic phenotype, and in some cases died, whereas leaves of the transgenic seedlings remained green (Figure 4A). Similar phenotypes were observed in three-week-old wild type and transgenic seedlings treated with $150 \mathrm{mM} \mathrm{NaCl}$ for $7 \mathrm{~d}$ under water culture (Additional file 4). Significantly, two transgenic lines (OE1and OE2) showed OsCYP2 overexpression under normal condition compared to wild-type (Figure 4B, C). Although $O s C Y P 2$ expression was inhibited in two transgenic lines and was induced in wild type under salt stress, salt-stressed seedlings of two transgenic lines showed close or higher levels of OsCYP2 expression to or than that of wild type (Figure 4C). Similarly, two transgenic lines showed higher levels of PPIase activity under normal condition compared to wild type. Saltstressed seedlings of wild type exhibited higher level of PPIase activity than unstressed seedlings, while no significant changes in levels of PPIase activity were found between salt-stressed and unstressed seedlings of two transgenic lines. Salt-stressed seedlings of two transgenic lines still kept close or higher levels of PPIase activity to or than that of wild type (Figure 4D). The addition of CsA significantly suppressed the PPIase activity of wild type and two transgenic lines (Figure 4D). Therefore, it 
A

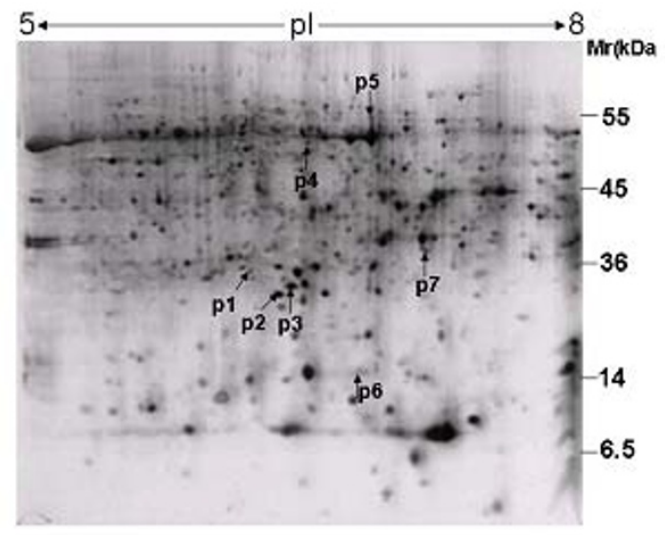

B

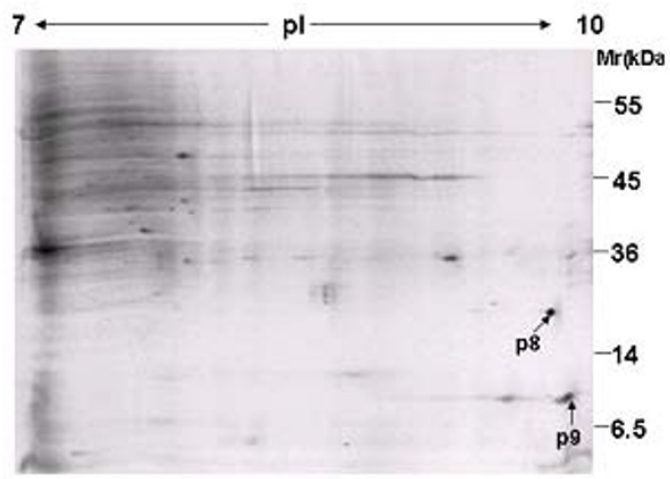

C

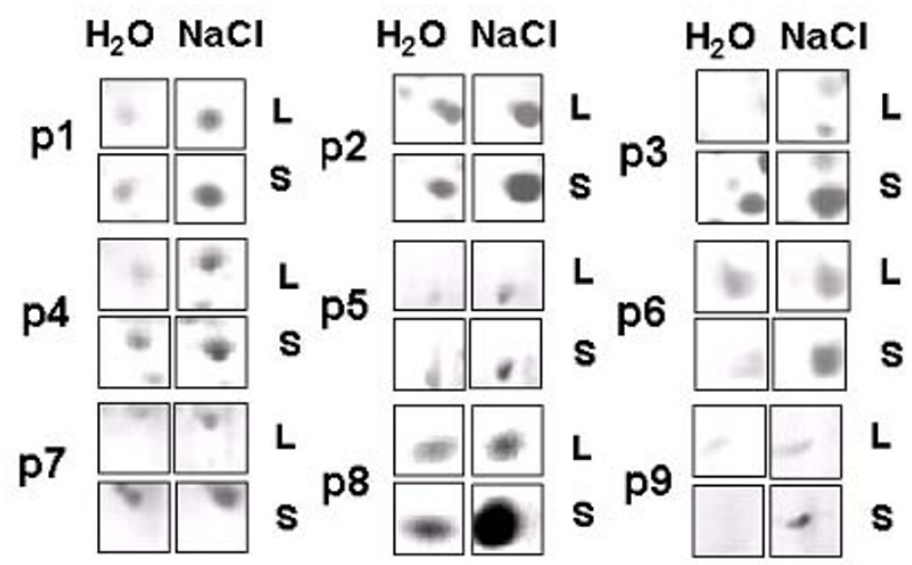

Figure 2 Two-dimensional gel electrophoresis analyses of shoot proteins in Shanyou 10 and Liangyoupeijiu. Rice shoot proteins separated by IEF/SDS-PAGE were stained with silver nitrate. Numbered spots represent proteins that were identified detailed in Table 1. (A) Total protein $(120 \mu \mathrm{g})$ from rice shoots of Shanyou 10 treated with $100 \mathrm{mM} \mathrm{NaCl}$ was loaded onto a 17-cm IPG gel with pH 5-8. SDS-PAGE (12\% gel) was used in the second-dimension separation. Gels were stained with silver nitrate solution. Numbers on the right represent apparent molecular masses. Numbers above gels represent isoelectric point range of separated proteins. (B) Total protein $(200 \mu \mathrm{g})$ from rice shoots of Shanyou 10 treated with $100 \mathrm{mM} \mathrm{NaCl}$ was loaded onto a 17-cm IPG gel with pH 7-10. (C) The nine proteins of interest (p1-p9) that were differentially expressed are shown. $S$ and $L$ denote Shanyou 10 and Liangyoupeijiu, respectively. 
Table 1 Identification of shoot proteins of interest in hybrid rice by MALDI-TOF MS

\begin{tabular}{|c|c|c|c|c|c|c|c|c|c|}
\hline $\begin{array}{l}\text { Spot } \\
\text { No. }{ }^{a}\end{array}$ & $\begin{array}{l}\text { Apparent MW } \\
(\mathrm{KD}) / \mathrm{pl}^{\mathrm{b}}\end{array}$ & $\begin{array}{l}\text { MatchMW } \\
(\mathrm{KD}) / \mathrm{pl}^{\mathrm{c}}\end{array}$ & $\begin{array}{l}\text { MOWSE } \\
\text { Score }^{d}\end{array}$ & $\begin{array}{l}\text { MOWSE Score for } \\
\text { acceptance }^{\text {e }}\end{array}$ & $\begin{array}{l}\text { No. } \\
\text { MP }^{f}\end{array}$ & $\begin{array}{l}\text { No. } \\
\text { UMPg }\end{array}$ & $\begin{array}{l}\text { Percent } \\
\text { covered }^{h}\end{array}$ & $\begin{array}{l}\text { Accession } \\
\text { No.' }\end{array}$ & Protein name \\
\hline P1 & $26.4 / 5.80$ & $25.64 / 5.82$ & 61 & 60 & 5 & 16 & 26 & Q9FUE6 & $\begin{array}{l}\text { Putative glutathione S- } \\
\text { transferase }\end{array}$ \\
\hline P2 & $23.8 / 5.85$ & $24.98 / 6.50$ & 69 & 60 & 6 & 36 & 43 & AAA57131 & $\begin{array}{l}\text { manganese superoxide } \\
\text { dismutase }\end{array}$ \\
\hline P3 & $24.2 / 5.91$ & $23.555 / 5.81$ & 62 & 60 & 4 & 17 & 28 & Q84UH5 & dehydroascorbate reductase \\
\hline P4 & $52.5 / 6.05$ & $52.688 / 5.85$ & 92 & 60 & 8 & 11 & 28 & NP_910282 & $\begin{array}{l}\text { putative phosphogluconate } \\
\text { dehydrogenase }\end{array}$ \\
\hline P5 & $65.5 / 6.5$ & $71.06 / 6.54$ & 61 & 60 & 6 & 15 & 16 & Q6Z836 & Putative L-aspartate oxidase \\
\hline P6 & $17.5 / 6.32$ & $18.682 / 6.28$ & 84 & 60 & 6 & 33 & 49 & XP_479920 & putative cold shock protein-1 \\
\hline P7 & $36.2 / 6.95$ & $30.783 / 6.99$ & 80 & 60 & 5 & 26 & 31 & CAE76006 & Prohibitin \\
\hline P8 & $18.5 / 9.21$ & $18.319 / 8.61$ & 117 & 60 & 10 & 4 & 42 & AAA57046 & Cyclophilin 2 (OsCYP2) \\
\hline P9 & $10.2 / 9.65$ & $22.566 / 9.8$ & 117 & 60 & 7 & 4 & 37 & XP_478627 & $\begin{array}{l}\text { Putative oxygen -evolving } \\
\text { enhancer protein 3-1 }\end{array}$ \\
\hline
\end{tabular}

${ }^{\mathrm{a}}$ Spot Nos refer to spot number as given in Figure 2. ${ }^{\mathrm{b}} \mathrm{Apparent} \mathrm{MW}(\mathrm{KD}) / \mathrm{pl}$ : apparent molecular weight and pl values. ${ }^{\mathrm{c}}$ MatchMW (KD)/pl: match molecular weight and pl values. ${ }^{\mathrm{d}}$ MOWSE Score: Scores given in MASCOT database. ${ }^{\mathrm{e}}$ MOWSE Score for acceptance: protein scores greater than 60 are significant $(p<0.05)$.

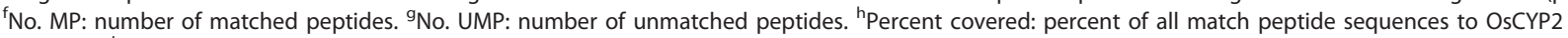
sequence. 'Accession No.: Accession number in NCBI database.

was suggested that OsCYP2 was likely to play an important role in the response of rice seedlings to salt stress.

Effect of salt stress on maximal photochemical efficiency (Fv/Fm) of OsCYP2 transgenic rice seedlings

Based on the observation that the OsCYP2-transgenic seedlings retained green color in their leaves, we speculated that OsCYP2 was likely to protect the photosynthetic components in rice leaves from oxidative stress caused by salt. We compared the effects of salt stress on the maximal photochemical efficiency (Fv/Fm) in OsCYP2 transgenic and wild-type seedlings. Salt stress significantly reduced the $\mathrm{Fv} / \mathrm{Fm}$ in wild-type seedlings, but no significant change was observed in Fv/Fm for OsCYP2 transgenic seedlings (Figure 5), suggesting that
OsCYP2 over-expression protected the photosynthetic components in rice leaves against oxidative stress.

Effect of salt stress on lipid peroxidation and ROS scavenging in OsCYP2 transgenic rice seedlings

To further validate the protective effects of OsCYP2 on the photosynthesis machinery in rice leaves, we compared salt stress-induced changes in the lipid peroxidation product (MDA) and ROS scavenging in OsCYP2-transgenic and wild-type seedlings. The level of MDA in plant tissues was used as an indicator of lipid peroxidation [11]. Under normal conditions (no $\mathrm{NaCl}$ treatment), the MDA levels were lower in OsCYP2-transgenic seedlings than in wild-type seedlings (Figure 6A). By comparison, under salt stress (200 mM NaCl), the MDA levels were significantly

Table 2 Identification of peptides from OsCYP2 (p8 protein spot) by MALDI-TOF-MS and ESI-MS/MS

\begin{tabular}{|c|c|c|c|c|c|c|c|}
\hline \multirow{2}{*}{$\begin{array}{l}\text { Peptide } \\
\text { no. }\end{array}$} & \multirow{2}{*}{$\begin{array}{l}\text { Match peptide } \\
\text { sequences }\end{array}$} & \multicolumn{2}{|c|}{ Methods of identification } & \multirow{2}{*}{$\begin{array}{c}\text { PercentCovered } \\
(\%)^{c}\end{array}$} & \multirow[t]{2}{*}{ Modifications } & \multirow{2}{*}{$\begin{array}{l}\text { Ion } \\
\text { score }\end{array}$} & \multirow{2}{*}{$\begin{array}{l}\text { lon score for } \\
\text { acceptance }\end{array}$} \\
\hline & & $\begin{array}{l}\text { MALDI-TOF } \\
\text { MS }\end{array}$ & $\begin{array}{l}\text { ESI-MS/ } \\
\text { MS }\end{array}$ & & & & \\
\hline 1 & VFFDMTVGGAPAGR & $+^{a}$ & + & 8.14 & None $^{d}$ & 64 & 38 \\
\hline 2 & TAENFR & + & $-b$ & 3.49 & None & $\mathrm{ND}^{\mathrm{e}}$ & ND \\
\hline 3 & TAENFRALCTGEK & + & - & 7.56 & None & ND & ND \\
\hline 4 & GSTFHR & + & - & 3.49 & None & ND & ND \\
\hline 5 & VIPEFMCQGGDFTR & + & + & 8.14 & $\begin{array}{c}\text { Carbamidomethyl } \\
\text { (C) }\end{array}$ & 79 & 38 \\
\hline 6 & GNGTGGESIYGEK & + & - & 7.56 & None & ND & ND \\
\hline 7 & GNGTGGESIYGEKFADEVFK & + & - & 11.63 & None & ND & ND \\
\hline 8 & FADEVFK & + & - & 4.07 & None & ND & ND \\
\hline 9 & HWFGR & + & - & 3.49 & None & ND & ND \\
\hline 10 & GGSTA KPV VIADCGQ LS & - & + & 9.88 & $\begin{array}{c}\text { Carbamidomethyl } \\
\text { (C) }\end{array}$ & 48 & 38 \\
\hline
\end{tabular}

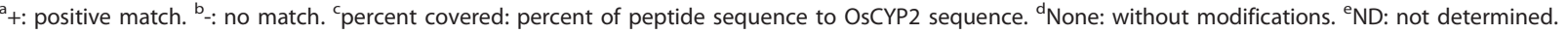
flon score for acceptance: individual ion score $>38$ indicate identity or extensive homology $(p<0.05)$. 


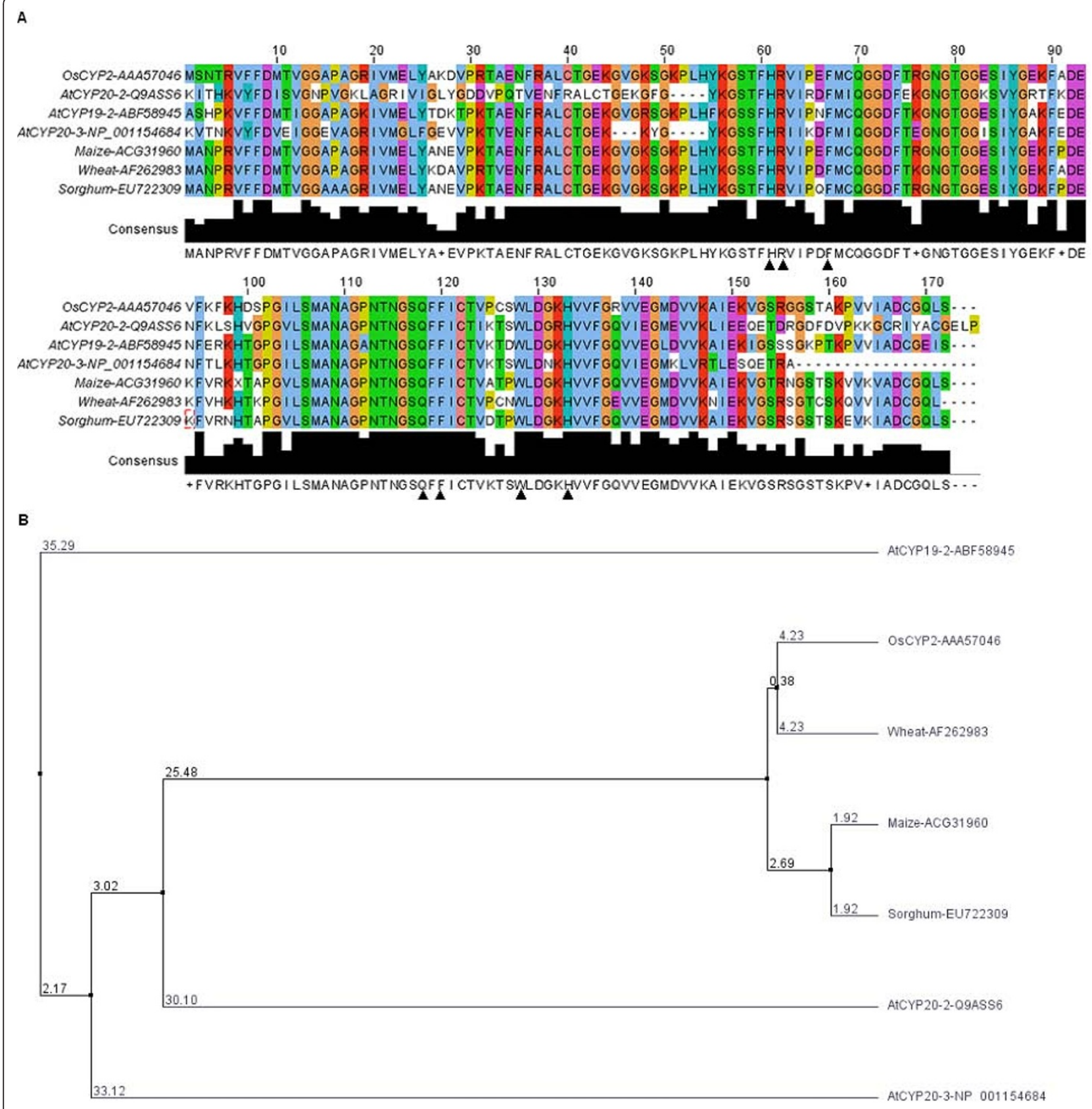

Figure 3 Multiple alignment of OsCYP2 with amino acid sequences of some plant cyclophilins. (A) Multiple sequence alignment of OsCYP2 with cyclophilins of various plant species by the Jalview multiple alignment editor. Seven residues (His-61, Arg-62, Phe-67, Gln-118, Phe120, Trp-128 and His-33) associated with PPlase catalysis are marked by filled triangle ( $\mathbf{\Delta})$. Three of these, His-61, Arg-62 and Phe-120, are extremely important for PPlase activity of OsCYP2. The residue Trp-128 is a binding site of OsCYP2 with cyclosporin A (CsA). (B) Dendrogram showing phylogenetic distance among plant cyclophilins according to average distance using percentage identity.

reduced in $O s C Y P 2$-transgenic seedlings, whereas the MDA levels increased in wild-type seedlings (Figure 6A), indicating that $O s C Y P 2$ over-expression could decrease lipid peroxidation levels in transgenic rice seedlings.

Stress-induced $\mathrm{H}_{2} \mathrm{O}_{2}$ accumulation could increase lipid peroxidation [12]. Under normal conditions, OsCYP2-transgenic rice seedlings contained lower $\mathrm{H}_{2} \mathrm{O}_{2}$ levels than wild-type seedlings. At $24 \mathrm{~h}$ after treatment with $200 \mathrm{mM} \mathrm{NaCl}$, each type of seedlings exhibited a decrease in $\mathrm{H}_{2} \mathrm{O}_{2}$ levels (Figure 6B). Similarly, the $\mathrm{H}_{2} \mathrm{O}_{2}$ levels in OsCYP2-transgenic rice seedlings were lower than that in wild-type seedlings.

Accumulation of $\mathrm{H}_{2} \mathrm{O}_{2}$ was accompanied by changes in ROS scavenging enzyme activities $[13,14]$. Here, we 


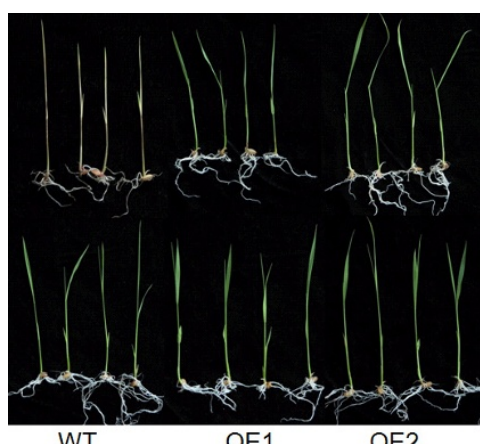

$200 \mathrm{mM} \mathrm{NaCl}$

Control $\left(\mathrm{H}_{2} \mathrm{O}\right)$

B

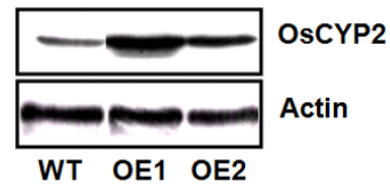

C

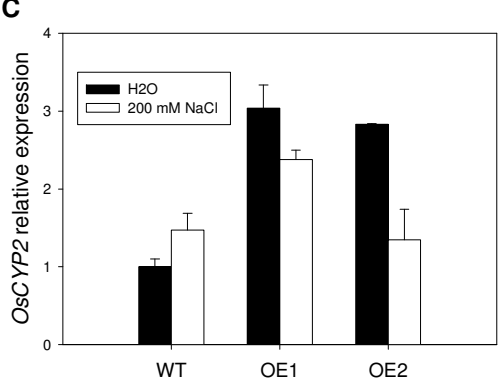

D

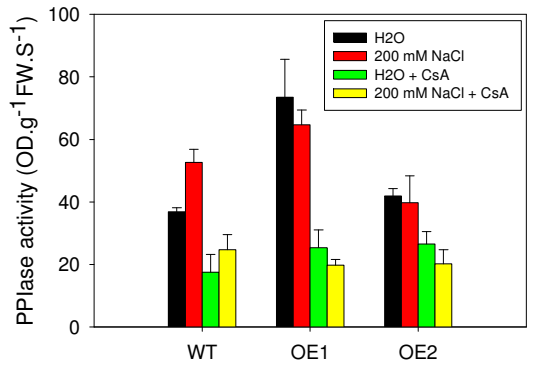

Figure 4 Phenotypes of rice seedlings under salt stress. (A) OsCYP2 transgenic rice lines showed salt tolerant phenotypes. Tenday-old rice seedlings were treated with $200 \mathrm{mM} \mathrm{NaCl}$. After 5 days, phenotypes of rice seedlings were observed. WT represents the wild-type seedling, Aichi ashahi that was used as a reference rice cultivar. (B) Western blot showed OsCYP2 overexpression in two OsCYP2 transgenic lines (OE1 and OE2). The housekeeping protein, Actin (Os03g0718100), was used as equal loading control. (C) Real time PCR exhibited differential expression pattern of OsCYP2 between WT and OsCYP2 transgenic lines (OE1 and OE2) under salt stress. Ten-day-old rice seedlings were treated for $1 \mathrm{~d}$ with $200 \mathrm{mM}$ $\mathrm{NaCl}$. An actin gene, Os03g0718100, was used as internal standard. (D) The altered activity of PPlase was found in WT and OSCYP2 transgenic lines (OE1 and OE2) under salt stress. Ten-day-old rice seedlings were treated for $1 \mathrm{~d}$ with $200 \mathrm{mM} \mathrm{NaCl}$. Cyclosporin A (CSA) was able to partly inhibit the activity of PPlase.

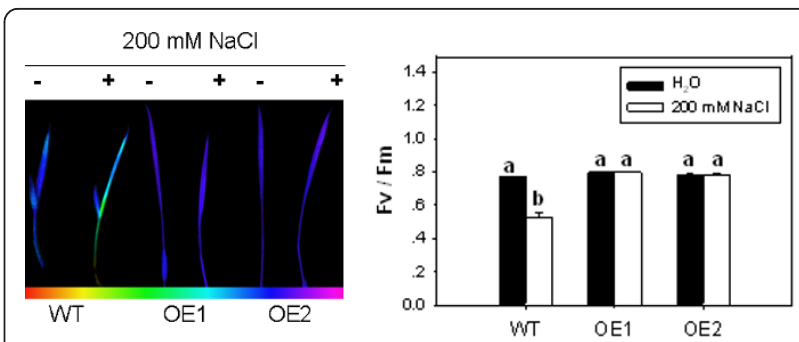

Figure 5 Effect of salt stress on Fv/Fm of rice seedlings. Under salt stress, lower Fv/Fm values were observed in wild-type seedlings, but no significant changes in Fv/Fm levels were observed in OsCYP2 transgenic rice lines. Ten-day-old rice seedlings of wildtype or OsCYP2-transgenic lines were used. Ten-day-old rice seedlings were treated with $200 \mathrm{mM} \mathrm{NaCl}$ for $24 \mathrm{~h}$. Fluorescence from red to pink color represents values from minimal to maximal readout. Each value is the mean \pm S.E. of six treatments. Identical letters above a pair of bars indicate there is no statistically significant difference among the transgenic lines at the $p=0.05$ level according to Duncan's multiple range test.

compared salt stress-induced alterations in the activities of the antioxidant enzymes superoxide dismutase (SOD), catalase (CAT) and ascorbate peroxidase (APX) in OsCYP2 transgenic and wild-type seedlings. Salt treatment increased the activities of these enzymes in OsCYP2 transgenic seedlings to varying degrees (Figure $6 \mathrm{C}, \mathrm{D}$ and $6 \mathrm{E}$ ). For wild-type seedlings, CAT activity increased (to a lesser degree than for transgenic seedlings) but the activities of SOD and APX decreased in response to salt stress.

\section{Expression pattern of OsCYP2 in hybrid rice seedlings}

To better understand OsCYP2 function, we utilized RTPCR to detect temporal and spatial expression patterns of OsCYP2 in hybrid rice seedlings. Based on the data in Figure 7A, it appeared that the OsCYP2 expression in roots was less than that in shoots. OsCYP2 expression was strongly induced by salt stress (Figure 7B). At different time points $(0,3,6,12,24$ and $48 \mathrm{~h})$ after salt treatment (100 mM NaCl), OsCYP2 exhibited circadian rhythm expression as time went. Maximal OsCYP2 expression occurred at $3 \mathrm{~h}$ in Shanyou 10 seedlings and at $6 \mathrm{~h}$ in Liangyoupeijiu seedlings, whereas minimal OsCYP2 expression occurred at $12 \mathrm{~h}$ in Shanyou 10 and Liangyoupeijiu seedlings (Figure 7B). Another peak of OsCYP2 expression appeared at $24 \mathrm{~h}$ in Shanyou 10 seedlings but not significantly in Liangyoupeijiu seedlings. Interestingly, Shanyou 10 seedlings showed higher maximal OsCYP2 expression than Liangyoupeijiu seedlings (Figure 7B). In addition to salt stress, OsCYP2 expression was affected by other types of stresses-PEG, heat, cold, or ABA. In Shanyou 10 and Liangyoupeijiu seedlings, OsCYP2 expression was induced by PEG and heat but inhibited by cold (Figure 7C). ABA slightly induced expression in Shanyou 10 
A

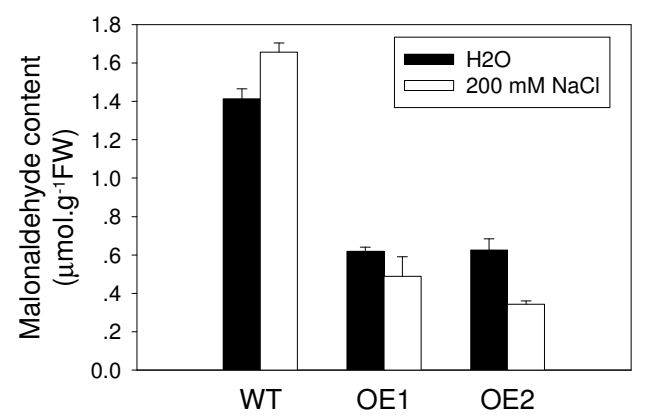

C

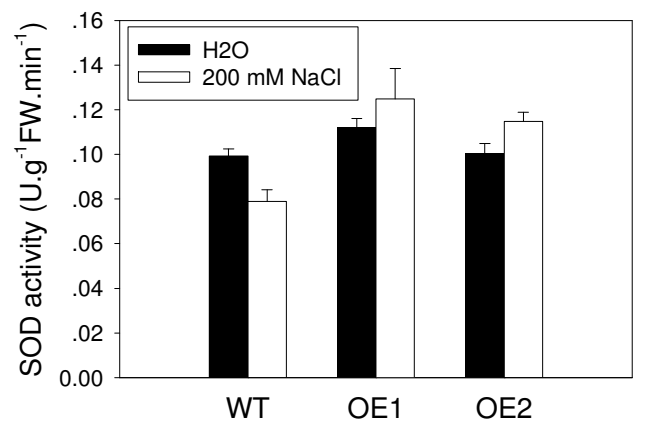

E

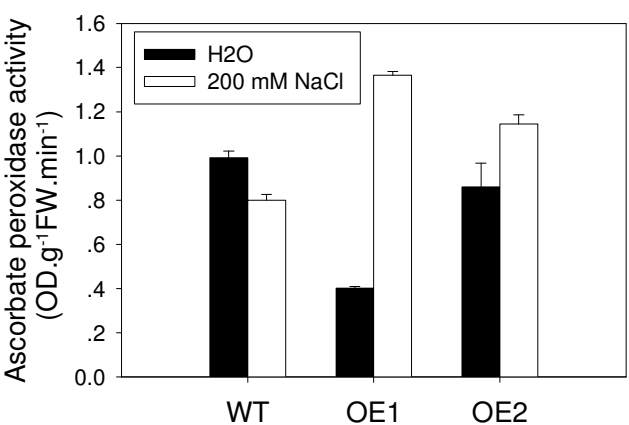

B

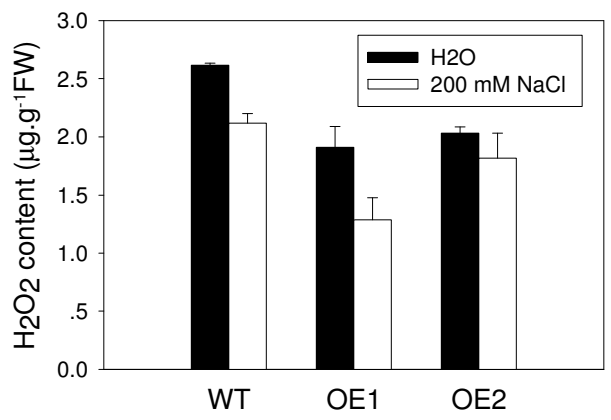

D

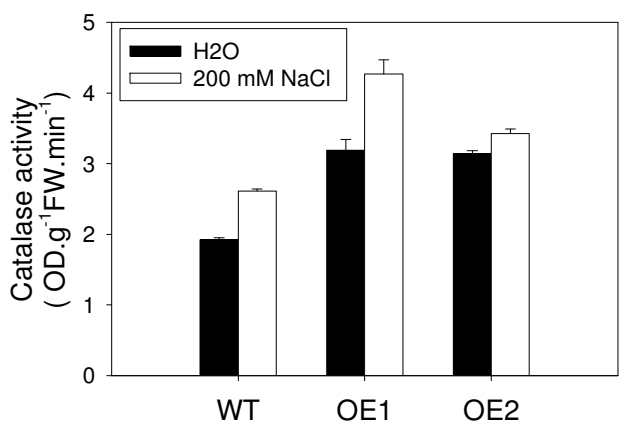

Figure 6 Comparison of lipid peroxidation and ROS scavenging of OsCYP2-transgenic rice seedlings and wild-type seedlings under salt stress. OsCYP2-transgenic rice seedlings had lower malonaldehyde (MDA) content and $\mathrm{H}_{2} \mathrm{O}_{2}$ and higher antioxidant enzyme activities than wild-type seedlings. Ten-day-old rice seedlings were treated with $200 \mathrm{mM} \mathrm{NaCl}$ for $24 \mathrm{~h}$. The levels of MDA (A) and $\mathrm{H}_{2} \mathrm{O}_{2}$ (B) were determined with thiobarbituric acid (TBA) and ferric-xylenol orange complex, respectively. The activities of antioxidant enzymes SOD (C), CAT (D), and APX

(E) were assayed. Each value was the mean \pm S.E. of four treatments.

seedlings but inhibited expression in Liangyoupeijiu seedlings. Generally, Shanyou 10 seedlings showed higher OsCYP2 expression than Liangyoupeijiu seedlings under the above mentioned stresses.

\section{Discussion}

The amino acid sequence alignment shows that OsCYP2 is likely to have peptidyl-prolyl cis-trans isomerase (PPIase or rotamase) activity, which catalyzes the cis-trans isomerization of the amide bond between a proline residue and the preceding residue, and functions as a molecular chaperone involved in protein folding, and refolding of denatured proteins. OsCYP2 possesses seven residues, including His-61, Arg-62, Phe-67, Gln-118, Phe-120, Trp128 and His-33 that show to be associated with PPIase catalysis. Three of these, including His-61, Arg-62 and Phe-120, are most essential for PPIase activity of OsCYP2. The residue Trp-128 is a site binding to cyclosporin A. 
A

Shanyou 10 Liangyoupeijiu

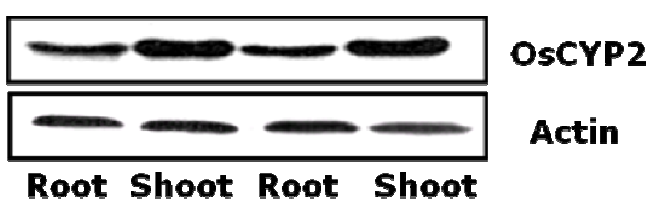

B

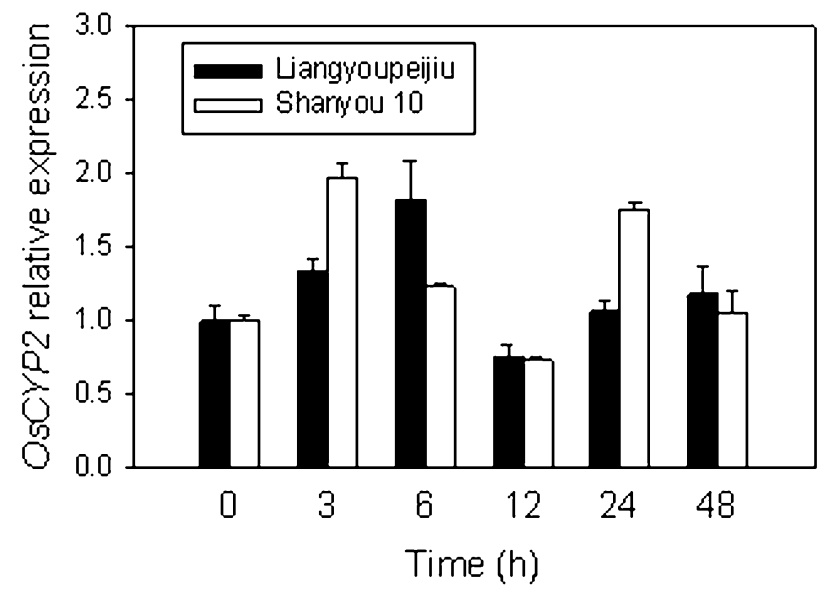

C

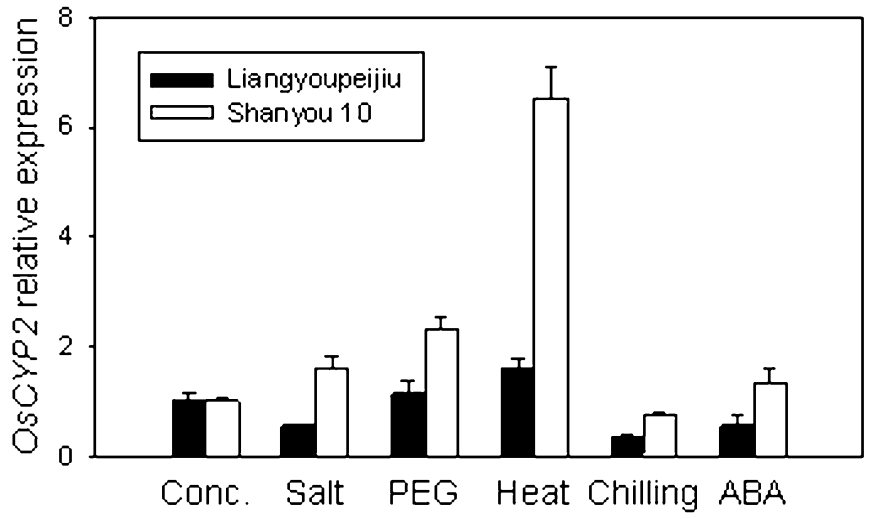

Figure 7 Expression of OsCYP2 in hybrid rice seedlings. (A) West blot showed expression of OSCYP2 in roots and shoots in 10-day-old rice seedlings. (B) RT-PCR showed time-course expression of OSCYP2 in seedlings of rice hybrid varieties, Shanyou 10 and Liangyoupeijiu, treated with $100 \mathrm{mM} \mathrm{NaCl}$. (C) RT-PCR showed expression of OsCYP2 in hybrid seedlings under various stresses. Conc.: non-treated controls. Salt: $100 \mathrm{mM} \mathrm{NaCl}$ at $25^{\circ} \mathrm{C}$ for $3 \mathrm{~h}$. PEG: $20 \%$ (w/v) PEG at $25^{\circ} \mathrm{C}$ for 3 h. Heat: $45^{\circ} \mathrm{C}$ for 3 h. Cold treatment: $4^{\circ} \mathrm{C}$ for 3 h. ABA: $50 \mathrm{mM} \mathrm{ABA}$ at $25^{\circ} \mathrm{C}$ for $3 \mathrm{~h}$. Expression of OsCYP2 in hybrid rice seedlings was analyzed by RT-PCR. Actin (Os03g0718100) was used as an internal standard.

Seven residues were also found in AtCYP20-2 that had the PPIase activity. In our study, two transgenic lines with OsCYP2 overexpression maintain higher levels of total PPIase activity compared to wild type. The addition of CsA is able to reduce total PPIase activity of both wild type and two transgenic lines. Although it has been demonstrated by heterologous expression that OsCYP2 possessed PPIase activity [9], our findings provide powerful evidence at in vivo level to validate it.

The mechanisms of plant response or tolerance to salt stress can fall into three categories: tolerance to osmotic stress, $\mathrm{Na}^{+}$exclusion from leaf blades and tissue tolerance [15]. Osmotic stress response is the first phase that plant responds to salt stress, resulting in the decrease in 
the rate of leaf growth and rate of photosynthesis. The reduced rate of photosynthesis accelerates the formation of ROS, and increases the activity of enzymes that detoxify ROS [16,17]. These enzymes include SOD, APX, CAT, and the various peroxidases $[16,18]$. The coordinated activity of the multiple forms of these enzymes in the different cell compartments maintain a balance between the rate of formation and removal of ROS, and control $\mathrm{H}_{2} \mathrm{O}_{2}$ at the levels required for cell signaling. Ionic stresses occur at a later stage, which then leads to senescence of mature leaves. The main site of $\mathrm{Na}^{+}$toxicity for most plants is the leaf blade, where $\mathrm{Na}^{+}$accumulates after being deposited in the transpiration stream rather than in the roots [19]. Most $\mathrm{Na}^{+}$that is transported to the shoot remains in the shoot, because for most plants, the movement of $\mathrm{Na}^{+}$ from the shoot to the roots in the phloem can likely recirculate only a small amount of the $\mathrm{Na}^{+}$that is transported to the shoot [15]. Therefore, $\mathrm{Na}^{+}$accumulation in the shoot is dependent on the net delivery of $\mathrm{Na}^{+}$ into the root xylem. Interestingly, several genes that are involved in controlling the net delivery of $\mathrm{Na}^{+}$into the root xylem have been identified. The plasma membrane $\mathrm{Na}^{+} / \mathrm{H}^{+}$antiporter, SOS1, is expressed in stelar cells and could be involved in the efflux of $\mathrm{Na}^{+}$from stelar cells into the xylem [15]. Meanwhile, SOS1 has also been implicated in retrieval of $\mathrm{Na}^{+}$from the xylem [20]. Moreover, there is much evidence showing that some members of the high-affinity $\mathrm{K}^{+}$transporter $(H K T)$ gene family play important role in retrieval of $\mathrm{Na}^{+}$from the xylem. AtHKT1;1, a member of Arabidopsis HKT gene family, that is involved in the retrieval of $\mathrm{Na}^{+}$from the xylem before it reaches the shoot [15]. A similar function for the closely related $H K T 1 ; 5$ gene family has been identified in rice [3] and wheat [21-23]. Unlike SOS1 or members of HKT gene family, OsCYP2, encodes a rice cyclophilin, inferring that it is likely to function as a molecular chaperone that is involved in protein folding. Over-expression of OsCYP2 confers salt tolerance in rice. However, higher leaf or root $\mathrm{K}^{+} / \mathrm{Na}^{+}$ ratio was not shown in OsCYP2 transgenic seedlings under salt stress as compared to wild type (Additional file 5), suggesting that OsCYP2 is not implicated in $\mathrm{Na}^{+}$ accumulation and transport in rice seedlings. Similarly, OsCYP2 transgenic seedlings displayed lower free proline level than wild type (Additional file 6), indicating that OsCYP2 does not play a role in osmotic protection of rice seedlings against salt stress. Interestingly, wildtype seedlings exhibited a marked reduction in maximal photochemical efficiency under salt stress, whereas no such change was observed for OsCYP2-transgenic seedlings. OsCYP2-transgenic seedlings had lower levels of lipid peroxidation products and higher activities of antioxidant enzymes than wild-type seedlings. However, no significant correlations were found between gene expression level and activity level of antioxidant enzymes (Additional file 7, 8). It is suggested that $\mathrm{H}_{2} \mathrm{O}_{2}$ levels are controlled by OsCYP2 up-regulating the activities of SOD, CAT, and APX at post-translation level, not at transcription level, thus resulting in reduced MDA level. This, in turn, protected photosynthesis components of rice leaves against oxidative stress by maintaining the activity of PSII. Therefore, OsCYP2 may be a key regulator that controls ROS level by modulating activities of antioxidant enzymes at translation level.

Here, our results show that OsCYP2 plays a key role in preventing oxidative damage to photosystems. Generally, the two processes that avoid photoinhibition owing to excess light are heat dissipation by the xanthophyll pigments and electron transfer to oxygen acceptors other than water. The latter response necessitates the upregulation of key enzymes for regulating ROS levels such as SOD, APX, CAT, and the various peroxidases $[16,18]$. Obviously, the above knowledge leads us to infer that OsCYP2 may be implicated in the process of electron transfer to oxygen acceptors. However, sufficient evidence is still lacking, further studies are needed to address this possibility.

In this study, OsCYP2 expression is induced by salt stress. Interestingly, OsCYP2 shows circadian rhythm expression as time goes. As a result, we speculate that response of OsCYP2 to salt stress is likely to be regulated by circadian rhythm. Moreover, circadian rhythm expression of OsCYP2 in Shanyou 10, a salt-tolerant hybrid variety, occurs earlier than that in Liangyoupeijiu, a salt-sensitive hybrid variety, suggesting earlier response of OsCYP2 to salt stress is likely to be associated with salt tolerance of rice seedlings. In addition to salt stress, OsCYP2 expression is affected by other types of stresses-PEG, heat, or ABA induced expression in Shanyou 10 seedlings but inhibited expression in Liangyoupeijiu seedlings. In addition, cold stress inhibits OsCYP2 expression in Shanyou 10 and Liangyoupeijiu seedlings. These data suggest that OsCYP2 expression is not specific in salt stress, but is ubiquitous in the response of rice seedlings to other types of stresses, including drought, heat and cold. Importantly, the above conclusion is consistent with the previous findings that OsCYP2 can respond to various stresses including high salt, drought, heat, oxidative stress and hypoxia stress $[9,24]$. Therefore, we speculate that OsCYP2 may function as a key integrator in response to multiple stresses.

\section{Conclusions}

Comparative proteomics identified a rice cyclophilin, OsCYP2 that is up-regulated during salt-induced stress. Over-expression of OsCYP2 confers salt tolerance in rice. Under salt stress, OsCYP2 is likely to up-regulate 
the activities of antioxidant enzymes (SOD, CAT, and APX) at post-translation level to control $\mathrm{H}_{2} \mathrm{O}_{2}$ levels, resulting in reduced MDA levels, which may prevent oxidative damage to photosystems. Unfortunately, OsCYP2 is not implicated in $\mathrm{Na}^{+}$accumulation and transport and osmotic protection in rice seedlings. OsCYP2 expression is not only induced by salt stress, but also regulated by circadian rhythm. Moreover, OsCYP2 is also likely to act as a key component that is involved in signal pathways of other type of stressesPEG, heat, cold, or ABA.

\section{Methods}

\section{Plant material and salt treatment}

Seeds of Shanyou 10 and Liangyoupeijiu were supplied by the Wu Wang Nong Seed Group (Hangzhou, Zhejiang province, China). Four replicates of 50 seeds for each treatment of each genotype were placed in germination boxes $(18 \mathrm{~cm} \times 13 \mathrm{~cm} \times 10 \mathrm{~cm})$ containing two layers of moistened blotters with $10 \mathrm{ml}$ of $100 \mathrm{mM}$ $\mathrm{NaCl}$. The seeds were germinated for 10 days at $25^{\circ} \mathrm{C}$. The $\mathrm{NaCl}$ solution was changed every day to maintain a constant concentration of $\mathrm{NaCl}$.

\section{Relative biomass and length of rice seedlings}

Four replicates of 10 fresh shoots or 10 fresh roots of 10-day-old seedlings for each treatment of each genotype were weighed. These shoots or roots were then oven dried at $70^{\circ} \mathrm{C}$ until they reached a constant dry weight (DW) [25]. The lengths of 10 shoots or 10 roots from the four replicates of 10-day-old seedlings for each treatment of each cultivar were measured. The distance from the basal part of shoot to tip of the longest leaf was calculated as the length of seedling. The standard error (SE) on the mean fresh weight (FW), dry weight (DW) or length of shoot and root was calculated. The percentage of relative FW, DW, or shoot/root length of the salt treated samples was calculated in relation to non-treated.

\section{Protein extraction}

The shoots of 10-day-old rice seedlings were harvested. $1 \mathrm{~g}$ FW of shoots were ground in liquid nitrogen and suspended in $5 \mathrm{ml}$ of $10 \%(\mathrm{w} / \mathrm{v})$ trichloroacetic acid in acetone with $0.07 \%(\mathrm{w} / \mathrm{v}) \beta$-mercaptoethanol at $-20^{\circ} \mathrm{C}$ for $1 \mathrm{~h}$, followed by centrifugation for $15 \mathrm{~min}$ at 35000 $\times g$. The pellets were resuspended in acetone with $0.07 \%$ $(\mathrm{w} / \mathrm{v}) \beta$-mercaptoethanol and incubated at $-20^{\circ} \mathrm{C}$ for $1 \mathrm{~h}$ and then centrifuged for $15 \mathrm{~min}$ at $4^{\circ} \mathrm{C}$. This step was repeated three times, and the pellets were lyophilized. The crude protein power was solubilized in lysis buffer (8 M urea, $2 \mathrm{M}$ thiourea, 4\% CHAPS, 0.5\% Ampholine (pH 3-10), $50 \mathrm{mM}$ DTT, and $1 \mathrm{mM}$ PMSF) for $1 \mathrm{~h}$ at room temperature, followed by centrifugation for
$15 \mathrm{~min}$ at $15000 \times g$. The supernatant was collected in a $1.5-\mathrm{ml}$ tube, and a $40 \mu \mathrm{l}$ sample was taken to determine the protein concentration. Protein concentration was determined using the Bradford assay with bovine serum albumin as the standard.

\section{2-D electrophoresis analysis}

For analytical and preparative gels of 2-DE, $120 \mu \mathrm{g}$ and $300 \mu \mathrm{g}$ of shoot proteins were loaded onto a single IPG gel strip (170 mm, pH 5-8 or pH 7-10, Bio-Rad, USA), respectively. IEF was carried out using the PROTEAN IEF system (Bio-Rad). IPG strips were rehydrated in rehydration buffer $(8 \mathrm{M}$ urea, $2 \%(\mathrm{w} / \mathrm{v})$ CHAPS, $0.5 \%(\mathrm{v} /$ v) Ampholine (pH 3-10), $50 \mathrm{mM}$ DTT and protein samples) for $12 \mathrm{~h}$ at $50 \mathrm{~V}$. IEF was performed in three steps: $250 \mathrm{~V}$ for $15 \mathrm{~min}, 10000 \mathrm{~V}$ for $5 \mathrm{~h}$ and then for a total of $60000 \mathrm{Vh}$ at $10000 \mathrm{~V}$. The gel strips were equilibrated in two steps: $6 \mathrm{ml}$ equilibration buffer I (6 M urea, 2\% SDS, $0.375 \mathrm{M}$ Tris- $\mathrm{HCl} \mathrm{pH}$ 8.8, 20\% (v/v) glycerol and $130 \mathrm{mM}$ DTT) for $10 \mathrm{~min}$ and $6 \mathrm{ml}$ equilibration buffer II (buffer I lacking DTT but containing $135 \mathrm{mM}$ iodoacetamide) for $10 \mathrm{~min}$.

\section{Image and data analysis}

Silver-stained gels were scanned using a Microtek 6180 scanner at a resolution of 600 dots per inch (dpi), and data were analyzed using PDQuest 8.0 software (BioRad). Specifically, gel image filter, spot detection, background subtraction and spot matching were performed. Prior to spot matching among gel images, one gel image was selected as a reference. After automatic matching, the unmatched spots of the member gels were added to the reference gel. The area of each spot was defined as the sum of the intensities of all pixels that made up the spot. To compare quantitative variations in intensity of protein spots, the spot areas were normalized as a percentage of the total area in all of the spots present in the gel. The resulting data from image analysis were transferred to PDQuest 8.0 software for query protein spots showing quantitative or qualitative variations.

\section{In-gel digestion, MALDI-TOF MS, and ESI-MS/MS analysis}

In-gel digestion of proteins was performed as described [26] with some modifications. Protein spots were excised from the preparative gels and washed twice with Milli-Q water, and then were destained twice for $5 \mathrm{~min}$ with $200 \mu \mathrm{l}$ of freshly prepared equi-volume solution of $100 \mathrm{mM}$ $\mathrm{Na}_{2} \mathrm{~S}_{2} \mathrm{O}_{3}$ and $30 \mathrm{mM} \mathrm{K} \mathrm{K}_{3} \mathrm{Fe}(\mathrm{CN})_{6}$. The samples were washed twice for 5 min with Milli-Q water and were cut into pieces, dried in a vacuum system, and then digested overnight at $37^{\circ} \mathrm{C}$ with $10 \mu \mathrm{g} / \mathrm{ml}$ sequencing-grade modified trypsin (Roche, Germany) in $25 \mathrm{mM} \mathrm{NH}_{4} \mathrm{HCO}_{3}$. The peptide mixtures were extracted with $40 \mu \mathrm{l} 0.5 \%$ trifluoroacetic acid for $1 \mathrm{~h}$ at $40^{\circ} \mathrm{C}, 40 \mu \mathrm{l} 0.25 \%$ trifluoroacetic acid in 
$50 \% \mathrm{ACN}$ for $1 \mathrm{~h}$ at $30^{\circ} \mathrm{C}$, and $25 \mu \mathrm{l} \mathrm{ACN}$ for $5 \mathrm{~min}$, respectively. All three extracts for each sample were combined and lyophilized. The resulting lyophilized tryptic peptides were dissolved in $5 \mathrm{mg} / \mathrm{ml} \alpha$-cyano-4-hydroxycinnamic acid (CHCA) containing 50\% $\mathrm{ACN}$ and $0.1 \%$ trifluoroacetic acid. MS analysis of tryptic peptides was performed using a MALDI-TOF mass spectrometer (reflex; Bruker Daltonics, Germany). The peptide calibration standard "mono" (Bruker Daltonics) was used for internal calibration to ensure the accuracy of protein identification. Masslynx software (version 3.5) was used for peak-picking. The $\mathrm{S} / \mathrm{N}$ of peaks was set at three. Peaks below $1000 \mathrm{~m} / \mathrm{z}$ were ignored. Mass range was from 1000 up to $4000 \mathrm{~m} / \mathrm{z}$. Resolution was set at 10000 . The PMF data were analyzed using MASCOT searching tools (version 1.9, http://www.matrixscience.com Matrix Science, London, UK). NCBInr (version 20050513) and rice were selected as the database and taxonomy, respectively. All peptide masses were assumed to be monoisotopic and $[\mathrm{M}$ $+\mathrm{H}]^{+}$. Modifications of carbamidomethylation and oxidation were considered. The mass accuracy was set at \pm 100 $\mathrm{ppm}$, and the maximum number of missed cleavages was set at one. The identified protein had to have the top MASCOT score and $\geq 4$ matched peptides. The coverage of the protein by the matching peptides was $>10 \%$. Protein scores that were obtained from the analysis with Mascot software indicated the probability of a true positive identification $(\mathrm{p}<0.05)$ and must be at least 60 .

Several tryptic peptides of interest were analyzed using ESI MS/MS. Raw MS/MS data were processed using MaxEnt software (version 3) which performed peak list geneation. MASCOT search engine (version 1.9, http:// www.matrixscience.com; Matrix Science, London, UK) was used for all MS/MS ions search. NCBInr (version 20050513) and rice were selected as the database and taxonomy, respectively. All peptide masses were assumed to be monoisotopic and $[\mathrm{M}+\mathrm{H}]^{+}$. Cysteine carbamidomethylation and methionine oxidation were selected as variable modifications. One missing cleavage was allowed. Precursor error tolerance was set to $<0.2 \mathrm{Da}$ and MS/MS fragment error tolerance $<0.2 \mathrm{Da}$. The identified protein should have at least two peptides matched and individual ions scores greater than 38 with expected value $<0.05$. Maximal number of protein entries was set at five. Cut-off score for accepting individual MS/MS spectra was set at zero.

\section{Gene cloning and transformation}

The OsCYP2 coding region was obtained by RT-PCR amplification with the following primers: OsCYP2-F, 5'TCTAGAATGTCGAACACGAGGGTGTT-3'; OsCYP2$\mathrm{R}$, 5'-GGTACCCTAGGAGAGCTGGCCGCAGT-3'. PCR products were recovered with a glass milk kit (BioDev Company, Beijing, China). Recovered fragments were ligated into the PMD18-T vector (TaKaRa, Japan). The ligated products were then transformed into $E$. coli DH5 $\alpha$ competent cells (TaKaRa, Japan). Twenty positive colonies were selected and identified by PCR. The positive plasmids extracted from these colonies were digested with EcoRI or PstI (TaKaRa, Japan) to confirm that target fragments were inserted into PMD18-T, and then positive plasmids were sequenced using an $\mathrm{ABI}$ 3700 (ABI, USA).

Each correct PCR fragment was digested with XbaI and KpnI and inserted into the binary vector pCAMBIA1300based super promoter [27]. Agrobacterium strain EHA105 was introduced into rice (O. sativa cv. Aichi ashahi) using Agrobacterium-mediated transformation [28,29]. A total of 120 lines of hygromycin- resistant $(1 \mu \mathrm{g} / \mathrm{ml})$ transgenic plants were selected, and their T3 plants were analyzed for phenotypic changes under salt stress.

\section{Phenotypic analysis of OsCYP2 transgenic seedlings under salt stress}

Three replicates of 50 T3-transgenic rice seeds with a single copy insertion of hygr $^{+}$(Additional file 3) or wildtype seeds were placed in germination boxes $(18 \mathrm{~cm} \times$ $13 \mathrm{~cm} \times 10 \mathrm{~cm}$ ) containing two layers of blotters moistened with distilled water. The boxes were then transferred to the chamber, and seeds were germinated at $25^{\circ} \mathrm{C}$ under $16 \mathrm{~h}$ light $/ 8 \mathrm{~h}$ dark at an illumination intensity of $60 \mathrm{mmol} \mathrm{m}^{-2} \mathrm{~s}^{-1}$ for 10 days. Transgenic and wild-type seedlings were transferred to germination boxes $(18 \mathrm{~cm} \times 13 \mathrm{~cm} \times 10 \mathrm{~cm})$ containing two layers of blotters moistened with $200 \mathrm{mM} \mathrm{NaCl}$ solution or distilled water. After 5 days, the phenotypes of seedlings were observed and photographed using a digital camera.

\section{Assay of maximal photochemical efficiency ( $\mathrm{Fv} / \mathrm{Fm})$}

Chlorophyll fluorescence was determined with chlorophyll fluorescence imaging system (IMAGING PAM; Heinz Walz, Effeltrich, Germany). To measure the maximal quantum efficiency of PSII $(\mathrm{Fv} / \mathrm{Fm})$, rice seedlings were dark-adapted for $30 \mathrm{~min}$. The measured light intensity for normal light and saturating light were 1 and 10, respectively. Fv/Fm was also measured by FMS2 pulse amplitude fluorimeter (Hansatech Instruments Ltd., Kings Lynn, Norfolk, UK). Rice seedlings were maintained in darkness for $30 \mathrm{~min}$ before measurement of Fv/Fm. Minimal fluorescence (Fo) was measured under a weak pulse of modulating light over a 0.8 -s period, and maximal fluorescence (Fm) was obtained after a saturating pulse of $0.7 \mathrm{~s}$ at $8000 \mu \mathrm{mol} \mathrm{m} \mathrm{s}^{-2}$.

\section{Antioxidant enzyme extraction and activity assay}

For the enzyme assays, $0.5 \mathrm{~g} \mathrm{FW}$ of shoots were ground with $3 \mathrm{ml}$ of ice-cold $25 \mathrm{mM}$ sodium phosphate buffer ( $\mathrm{pH}$ 7.8) containing $0.2 \mathrm{mM}$ EDTA, $2 \mathrm{mM}$ ascorbate 
acid (AsA) and 2\% (w/v) polyvinylpyrrolidone. The suspensions were centrifuged at $4^{\circ} \mathrm{C}$ for $20 \mathrm{~min}$ at $12,000 \times$ $g$, and the resulting supernatants were used to determine enzymatic activity. Superoxide dismutase (SOD) activity was assayed by measuring the ability to inhibit the photochemical reduction of nitroblue tetrazolium (NBT) as described [30]. Catalase (CAT) activity was measured as the decline in absorbance at $240 \mathrm{~nm}$ due to the decrease of extinction of $\mathrm{H}_{2} \mathrm{O}_{2}$ as described [31]. Ascorbate peroxidase (APX) was measured by the decrease in absorbance at $290 \mathrm{~nm}$ as described [32].

\section{Determination of MDA and $\mathrm{H}_{2} \mathrm{O}_{2}$ content in rice shoots}

Lipid peroxidation was measured as the amount of malondialdehyde (MDA) determined by the TBA reaction as described [33]. Shoot samples $(0.5 \mathrm{~g})$ were homogenized in $3 \mathrm{ml}$ of $50 \mathrm{mM}$ PBS (pH 7.8) containing $2 \%(\mathrm{v} / \mathrm{v})$ polyvinylpyrrolidone, and then centrifuged at $15,000 \times g$ for $20 \mathrm{~min}$. Three $\mathrm{ml}$ of $10 \%(\mathrm{w} / \mathrm{v})$ trichloroacetic acid containing $0.6 \%(\mathrm{w} / \mathrm{v}) \mathrm{TBA}$ was added to $1 \mathrm{ml}$ of the supernatant aliquot. The mixture was heated at $100^{\circ} \mathrm{C}$ for $30 \mathrm{~min}$ and then quickly cooled in an ice bath. The mixtures were centrifuged at $10,000 \times g$ for $10 \mathrm{~min}$, and their absorbance was measured at $532 \mathrm{~nm}$. The value for nonspecific absorption at $600 \mathrm{~nm}$ was subtracted from the $532 \mathrm{~nm}$ reading. The MDA content was calculated using its extinction coefficient of $155 \mathrm{mM}^{-1} \mathrm{~cm}^{-1}$ and expressed as $\mu \mathrm{mol} \mathrm{g}{ }^{-1} \mathrm{FW}$.

Plant tissue $\mathrm{H}_{2} \mathrm{O}_{2}$ was extracted by cold acetone as described [33]. Shoots (1 g FW) were homogenized in $5 \mathrm{ml}$ cold acetone and then centrifuged at 10,000 $\times g$ for $10 \mathrm{~min}$. To $1 \mathrm{ml}$ of the supernatant aliquot, $3 \mathrm{ml}$ of extract containing a 3:1 (v/v) ratio of $\mathrm{CCl}_{4}$ and $\mathrm{CHCl}_{3}$ and $5 \mathrm{ml}$ of distilled water were added and mixed successively, and then centrifuged at $4,000 \times g$ for $1 \mathrm{~min}$. The supernatant was removed and tested for $\mathrm{H}_{2} \mathrm{O}_{2}$. $\mathrm{H}_{2} \mathrm{O}_{2}$ content was determined by ferric-xylenol orange complex as described [34].

\section{Peptidyl prolyl cis-trans activity assay}

Rice shoots $(0.3 \mathrm{~g} F W)$ were homogenized in $50 \mathrm{mM}$ Tris- $\mathrm{HCl}(\mathrm{pH} 8.0)$ containing $1 \mathrm{mM}$ EDTA, and centrifuged at $13000 \times \mathrm{g}$ for $15 \mathrm{~min}$ at $4^{\circ} \mathrm{C} .50 \mu \mathrm{l}$ supernatant was used for peptidyl prolyl cis-trans isomerase (PPIase) activity. PPIase activity was assayed in a coupled reaction with chymotrypsin, as described ${ }^{9}$ with some modifications. The assays were performed at $0^{\circ} \mathrm{C}$ for $120 \mathrm{~s}$. The $1 \mathrm{ml}$ assay mixture contained $80 \mu \mathrm{M} \mathrm{N}$-succinylala-ala-prophe-p-nitroanilidine (Sigma, USA) as test peptide and assay buffer [50 mM HEPES ( $\mathrm{pH} 8.0$ ), $150 \mathrm{mM} \mathrm{NaCl}, 0.05 \%$ Triton X-100], The reaction was initiated by the addition of $100 \mu$ l chymotrypsin $(5 \mathrm{mg} / \mathrm{ml})$ (Sigma, USA) and the change in absorbance at $390 \mathrm{~nm}$ was monitored using a spectrophotometer (Shimadzu
UV2550). Cyclophilin associated PPIase activities were determined by the extent of inhibition of reaction in the presence of cyclosporin A (Sigma, USA). The inhibitor was added to the assay mix $30 \mathrm{~min}$ before the start of the reaction and incubated at $4{ }^{\circ} \mathrm{C}$.

\section{Real-time PCR}

Frozen leaf tissue was homogenized in liquid nitrogen using a mortar and pestle. Total RNA was extracted using Trizol according to the supplier's recommendation (Invitrogen, Karlsruhe, Germany). Residual DNA was removed with an RNase-free DNase (Fermentas, EU). One microgram total RNA was reverse-transcribed using $0.5 \mu \mathrm{g}$ of Oligo (dT) 20 and 200 units of ReverTra Ace (TOYOBO, Japan) following the supplier's recommendation. Quantitative real time PCR was performed using the Opticon 2 Real-time PCR Detection System (Bio-Rad, Hercules, CA, USA). PCRs were performed using the SYBR Green Supermix (Bio-Rad). The PCR conditions consisted of 40 cycles of denaturation at $95^{\circ} \mathrm{C}$ for $30 \mathrm{~s}$, annealing at $59^{\circ} \mathrm{C}$ for $45 \mathrm{~s}$ and extension at $72^{\circ} \mathrm{C}$ for $30 \mathrm{~s}$. A dissociation curve was generated at the end of each PCR cycle to verify that a single product was amplified using software provided with the Opticon 2 Real-time PCR Detection System. To minimize sample variations, mRNA expression of the target gene was normalized relative to the expression of the housekeeping gene actin. All experiments were repeated three times for cDNA prepared for two samples. The quantification of mRNA levels is based on the method of Livak and Schmittgen (2001). The threshold cycle (Ct) value of actin (Os03g0718100) as internal standard was subtracted from that of the gene of interest to obtain a $\Delta \mathrm{Ct}$ value. The $\mathrm{Ct}$ value of untreated control sample was subtracted from the $\Delta \mathrm{Ct}$ value to obtain a $\Delta \Delta \mathrm{Ct}$ value. The fold changes in expression level relative to the control were expressed as $2^{-\Delta \Delta} \mathrm{Ct}$. The following primers were designed for gene-specific transcript amplification: OsCYP2-F: 5'-GCCTTTCGCCAGTATCAGTC-3', OsCYP2-R: 5'-CAGATCCAACTCCACCGAAT-3'; Actin-F: 5'-GACCTTGCTGGGCGTGAT-3', Actin-R: 5'-GTCATAGTCCAGGGCGATGT-3'.

\section{Preparation of antiserum and western blot analysis}

According to the OsCYP2 amino acid sequence, the peptide fragment 44-KGVGKSGKPLHYKG-57 was determined as a protein-surface antigen. The peptide containing an additional $\mathrm{N}$-terminal cysteine was synthesized and purified on a resin. The purified peptide was used to raise polyclonal antibodies in rabbits (HuaAn Biotechnology Co., Ltd., Hangzhou, China).

Rice shoots $(0.5 \mathrm{~g} \mathrm{FW})$ were ground into a fine powder in liquid nitrogen and then added to $2 \mathrm{ml}$ of protein extraction buffer containing $50 \mathrm{mM}$ Tris- $\mathrm{HCl}, \mathrm{pH} 8,1 \mathrm{mM}$ EDTA, $10 \mathrm{mM} \mathrm{NaCl}, 1 \% \mathrm{SDS}, 0.5 \%$ (v/v) 2-mercaptoethanol, 
$0.1 \mathrm{mM}$ PMSF, $0.1 \mathrm{mM}$ DTT and $0.1 \%$ (v/v) Triton X-100, and ground until shoot power was well homogenized. The mixtures were centrifuged at $4^{\circ} \mathrm{C}$ for $15 \mathrm{~min}$ at $14,000 \times g$, and the supernatant was transferred into a 5 - $\mathrm{ml}$ centrifuge tube. The protein concentration was determined using the $R C D C$ protein assay kit II (Bio-Rad, USA). Total protein $(20 \mu \mathrm{g})$ from each sample was subjected to electrophoresis on a $15 \%$ SDS-PAGE gel. Proteins in the gel were transferred to PVDF membranes by an electric transforming system, and the membranes were blocked with $5 \%(\mathrm{w} / \mathrm{v})$ skim milk. The blot was incubated with the rabbit antiserum raised against OsCYP2 diluted 1:1000 in TBST containing $25 \mathrm{mM}$ Tris base $\mathrm{pH} 8.0,140 \mathrm{mM} \mathrm{NaCl}, 3 \mathrm{mM} \mathrm{KCl}$ and $0.05 \%(\mathrm{v} / \mathrm{v})$ Tween 20 for $1 \mathrm{~h}$ and washed three times for 5 min each in TBST (Tris-buffered saline/Tween 20). The blot was then probed with the secondary antibody (HRPlabeled goat anti-rabbit IgG $(\mathrm{H}+\mathrm{L}))$ diluted 1:5000, and the reactive band was visualized using ECL (Multiscience Biotech Co., Ltd., Hangzhou, China).

\section{Statistical analysis}

The experimental design was set up with genotypes as main plots and treatments as subplots. The treatment combinations were completely randomized with respect to the placement of the germination boxes in a germination chamber with five layers of rack for each genotype. Three replications of the experiment were conducted on different dates. Analyses of variance (ANOVA) were conducted by Duncan's multiple range test. Before analysis of variance, percentages were transformed according to $\mathrm{y}=\arcsin [\operatorname{sqr}(\mathrm{x} / 100)]$. All data were analyzed according to a factorial model and replicates as random effects. Means were compared among treatments by LSD (least significant difference) at 0.05 confidence level.

\section{Additional material}

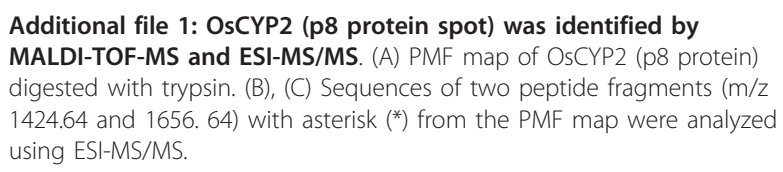

Additional file 5: The ratio of potassium (K) to sodium (Na) of rice seedlings under salt stress. Three-week-old rice seedlings were treated for $2 \mathrm{~d}$ with $150 \mathrm{mM} \mathrm{NaCl}$ under water culture condition. The total potassium or sodium content of rice shoots or roots was determined using atomic absorption spectroscopy, respectively. (A) Shoots. (B) Roots.
Additional file 6: The free proline content of rice seedlings under salt stress. Three-week-old rice seedlings were treated for $2 \mathrm{~d}$ with $150 \mathrm{mM}$ $\mathrm{NaCl}$ under water culture condition. The free proline content of rice shoots was determined by ninhydrin reaction.

Additional file 7: Expression pattern of antioxidant enzyme genes in transgenic rice seedling under salt stress. Ten-old rice seedlings were treated for $1 \mathrm{~d}$ with $200 \mathrm{mM} \mathrm{NaCl}$. Expression of several genes was quantified using real time PCR. (A) Gu/Zn- SOD (accession no. D01000.1) (B) Mn- SOD (accession no. L19436.1) (C) Fe- SOD (accession no. AY770495.1) (D) OsCat (accession no. AY339372.1) (E) OsCatC (accession no. AB020502) (F) mAPX (accession no. AY382617.1) (G) CAPX (accession no. AY254495.1) (H) SAPX (accession no. AB114855). The housekeeping gene, Actin (Os03g0718100) was used as internal standard.

Additional file 8: Correlations between activities of antioxidant enzymes and expression of corresponding genes.

\section{Abbreviations}

ABA: abscissic acid; APX: ascorbate peroxidase; CAT: catalase; CDNA: complementary DNA; CHAPS: 3[(cholamidopropy1) dimethylammonio]-1propane sulphonate; CSA: cyclosporin A; 2-D: two-dimensional; 2-DE: twodimensionsl polyacrylmide gel electrophoresis; DTT: dithiothreitol; DW: dry weight; EDTA: ethylenediaminetetraacetic acid; ESI-MS: electrospray Ionization mass spectrometry; FW: fresh weight; IEF: isoelectric focusing; IPG: immobilized pH gradient; MALDI-TOF: matrix-assisted laser desorptionionization time-of-flight; MDA: malonaldehyde; MS: mass spectrometry; MW: molecular weight; NBT: nitroblue tetrazolium; PAGE: polyacrylamide gel electrophoresis; PBS: phosphate buffer solution; PCR: polymerase chain reaction; PEG: polyethylene glycerol; PMF: peptide mass fingerprint; PMSF: phenylmethlsulfonyl fluoride; PPlase: peptidyl prolyl cis-trans isomerase; PSII: photosystem II; PVDF: polyvinylidend difluoride; PVP:

Polyvinylpyrrolidone; QTL: quantitative trait loci; ROS: reactive oxygen species; SDS: sodium dodecyl sulfate; SE: standard error; SOD: superoxide dismutase; SOS1: salt overly sensitive1; TBA: thiobarbituric acid; TCA: trichloroacetic acid.

\section{Acknowledgements}

We thank Dr. Wei-Hua Wu (China Agricultural University) for providing the Super 1300 vector for OsCYP2 overexpression in rice. We also thank Dr. Xianming Duan (Harris Moran Seed Company, USA), Dr. Yuxian Zhu (Peking University, China) and Dr. Zhi-Xin Xie (Texas Technical University, USA) for critical reading of the manuscript. This work was supported by National Great Special Project of breeding for new varieties of GMOs (Research Grant \#2009ZX08001-027B to H.-S. Ma and S.-L. R and \#2008ZX08010-004 to Y.-P. Fu.), the Natural Science Foundation of China (Research Grant \#30300218 to S.-L. R.), the Natural Science Foundation of Zhejiang province (Research Grant \#Y307016 to S.-L. R and \#Y3080229 to H.-Z. Chen.), the Project of Science and Technology of Zhejiang province (Research Grant \#2008C22077 to Y.P. Fu.), the Great Project of Science and Technology of Hangzhou City (Research Grant \#20072312A03 to S.-L. R.) and the Project of Hangzhou Research Institute (Research Grant 20061922, No. 4 to S.-L. R.).

\section{Author details}

'Plant Molecular Biology \& Proteomics Lab, Institute of Biotechnology, Hangzhou Academy of Agricultural Sciences, Hangzhou 310024, PR China. ${ }^{2}$ National Key Laboratory of Rice Biology, China National Rice Research Institute, Hangzhou 310006, PR China.

\section{Authors' contributions}

SLR carried out 2-DE analysis, conceived of the study, participated in its design and coordination and completed the manuscript. HSM carried out physiological analysis and participated in the design of the study. SHW carried out phenotypic analysis. YPF carried out gene cloning and transformation. YX participated in gene cloning and construction of binary vector. WZL carried out western blot analysis and participated in the sequence alignment. FW carried out RT-PCR analysis and biochemical assays. JXT participated in physiological analysis. SZW participated in gene transformation. HZC participated in phenotype identification and statistical analysis. All authors read and approved the final manuscript. 
Received: 7 June 2010 Accepted: 16 February 2011

Published: 16 February 2011

\section{References}

1. Kawasaki S, Borchert C, Deyholos M, Wang H, Brazille S, Kawai K, Galbraith D, Bohnert HJ: Gene expression profiles during the initial phase of salt stress in rice. Plant Cell 2001, 13:889-906.

2. Chao DY, Luo YH, Shi M, Luo D, Lin HX: Salt-responsive genes in rice revealed by CDNA microarray analysis. Cell Res 2005, 15:796-810,

3. Ren ZH, Gao JP, Li LG, Cai XL, Huang W, Chao DY, Zhu MZ, Wang ZY, Luan S, Lin HX: A rice quantitative trait locus for salt tolerance encodes a sodium transporter. Nat Genet 2005, 37:1141-11464.

4. Shi H, Lee BH, WU SJ, Zhu JK: Overexpression of a plasma membrane $\mathrm{Na}^{+} / \mathrm{H}^{+}$antiporter improves salt tolerance in Arabidopsis. Nat Biotechnol 2003, 21:81-85.

5. Abbasi F, Komatsu S: A proteomic approach to analyze salt-responsive proteins in rice leaf sheath. Proteomics 2004, 4:2072-2081.

6. Yan SP, Zhang QY, Tang ZC, Su WA, Sun WN: Comparative proteomic analysis provides new insights into chilling stress responses in rice. $\mathrm{Mol}$ Cell Proteomics 2006, 5:484-496

7. Parker R, Flowers TJ, Moore AL, Harpham NVJ: An accurate and reproducible method for proteome profiling of the effects of salt stress in the rice leaf lamina. J Exp Bot 2006, 57:1109-1118

8. Dooki AD, Mayer-Posner FJ, Askari H, Zaiee AA, Salekdeh GH: Proteomic responses of rice young panicles to salinity. Proteomics 2006, 6:6498-6507.

9. Kumari S, Singh P, Singla-Pareek SL, Pareek A: Heterologous expression of a salinity and developmentally regulated rice cyclophilin gene (OsCyp2) in E. coli and S. cerevisiae confers tolerance towards multiple abiotic stresses. Mol Biotechnol 2009, 42:195-204.

10. Buchholz WG, Harris-Haller L, DeRose RT, Hall TC: Cyclophilins are encoded by a small gene family in rice. Plant Mol Biol 1994, 25:837-843.

11. Li ZG, Song YQ, Gong M: Xylenol orange method used for the measurement of hydrogen peroxide in plant tissue. J Yunnan Normal Univ 2007, 27:50-54, (in Chinese).

12. Kuo MC, Kao CH: Aluminum effects on lipid peroxidation and antioxidative enzyme activities in rice leaves. Biol Plantarum 2003, 46:149-152.

13. Sairam RK, Deshmukh PS, Saxena DC: Role of antioxidant systems in wheat genotypes tolerance to water stress. Biol Plantarum 1998, 41:387-394.

14. Dixit $V$, Pandey $V$, Shyam R: Differential antioxidative responses to cadmium in roots and leaves of pea (Pisum sativum L. cv. Azad). J Exp Bot 2001, 52:1101-1109.

15. Munns R, Tester M: Mechanisms of Salinity Tolerance. Ann Rev Plant Biol 2008, 59:651-81.

16. Apel $\mathrm{K}$, Hirt $\mathrm{H}$ : Reactive oxygen species: metabolism, oxidative stress and signal transduction. Annu Rev Plant Biol 2004, 55:373-99.

17. Foyer $\mathrm{CH}$, Noctor $\mathrm{G}$ : Oxidant and antioxidant signalling in plants: a re-evaluation of the concept of oxidative stress in a physiological context. Plant Cell Environ 2005, 28:1056-71.

18. Logan BA: Reactive oxygen species and photosynthesis. In Antioxidants and Reactive Oxygen Species in Plants. Edited by: Smirnoff N. Oxford: Blackwell; 2005:250-67.

19. Munns R: Comparative physiology of salt and water stress. Plant Cell Environ 2002, 25:239-50.

20. Shi HZ, Quintero FJ, Pardo JM, Zhu JK: The putative plasma membrane Na ${ }^{+} / \mathrm{H}^{+}$antiporter SOS1 controls long-distance $\mathrm{Na}+$ transport in plants. Plant Cell 2002, 14:465-77.

21. Davenport RJ, Muňoz-Mayor A, Jha D, Essah PA, Rus A, Tester M: The $\mathrm{Na}^{+}$ transporter AtHKT1 controls xylem retrieval of $\mathrm{Na}^{+}$in Arabidopsis. Plant Cell Environ 2007, 30:497-507.

22. Byrt CS, Platten JD, Spielmeyer W, James RA, Lagudah ES, Dennis ES, Tester M, Munns R: HKT1;5-likecation transporters linked to $\mathrm{Na}^{+}$exclusion loci in wheat, Nax2 and Kna1. Plant Physiol 2007, 143:1918-1928.

23. James RA, Davenport RJ, Munns R: Physiological characterization of two genes for $\mathrm{Na}^{+}$exclusion in durum wheat: $\mathrm{Nax} 1$ and Nax2. Plant Physiol 2006, 142:1537-47.

24. Matsumura H, Nirasawa S, Terauchi R: Transcript profiling in rice (Oryza sativa $\mathrm{L}$.) seedlings using serial analysis of gene expression (SAGE). Plant J 1999, 20:719-726.
25. Khan MSA, Hamid A, Karim MA: Effect of sodium chloride on germination and seedling characters of different types of rice (Oryza sativa $\mathrm{L}$ ). J Agron \& Crop Sci 1997, 179:163-169.

26. Gharahdaghi F, Weinberg CR, Meagher DA, Imai BS, Mische SM: Mass spectrometric identification of proteins from silver-stained polyacrylamide gel: A method for the removal of silver ion to enhance sensitivity. Electrophoresis 1999, 20:610-605.

27. Yu XC, Zhu SY, Gao GF, Wang XJ, Zhao R, Zou KQ, Wang XF, Zhang XY, Wu FQ, Peng CC, Zhang DP: Expression of a grape calcium-dependent protein kinase ACPK1 in Arabidopsis thaliana promotes plant growth and confers abscisic acid-hypersensitivity in germination postgermination growth, and stomatal movement. Plant Mol Biol 2007, 64:531-538.

28. Hiei $Y$, Ohta $S$, Komari $T$, Kumashiro $T$ : Efficient transformation of rice (Oryza sativa L.) mediated by Agrobacterium and sequence analysis of the boundaries of the T-DNA. Plant J 1994, 6:271-282.

29. Liu QQ, Zhang JL, Wang ZY, Hong MM, Gu MH: A highly efficient transformation system mediated by Agrobacterium tumefaciences in rice (Oryza sativa L.). Acta Phytophysiol Sinica 1998, 24:259-27, (in Chinese).

30. Stewart RRC, Bewley JD: Lipid peroxidation associated with accelerated aging of soybean axes. Plant Physiol 1980, 65:245-248.

31. Patra HK, Kar M, Mishra D: Catalase activity in leaves and cotyledons during plant development and senescence. Biochem Physiol Pflanzen 1978, 172:385-390

32. Liu J, Lv B, Xu LL: An improved method for the determination of hydrogen peroxide in leaves. Progr Biochem Biophys 2000, 27:548-551, (in (hinese).

33. Heath RL, Packer L: Photoperoxidation in isolated chloroplast. I. Kinetics and stoichiometry of fatty acid peroxidation. Arch Biochem Biophys 1968, 125:189-198.

34. Nakano $Y$, Asada K: Hydrogen peroxide is scavenged by ascorbatespecific peroxidase in spinach chloroplasts. Plant Cell Physiol 1981, 22:867-880.

doi:10.1186/1471-2229-11-34

Cite this article as: Ruan et al:: Proteomic identification of OsCYP2, a rice cyclophilin that confers salt tolerance in rice (Oryza sativa L.) seedlings when overexpressed. BMC Plant Biology 2011 11:34.

\section{Submit your next manuscript to BioMed Central and take full advantage of:}

- Convenient online submission

- Thorough peer review

- No space constraints or color figure charges

- Immediate publication on acceptance

- Inclusion in PubMed, CAS, Scopus and Google Scholar

- Research which is freely available for redistribution

Submit your manuscript at www.biomedcentral.com/submit
C Biomed Central 